\title{
Estresse, Doença do Tempo: um estudo sobre o uso do tempo pelos executivos brasileiros
}

\section{Stress, a Disease Related to Time: a study about Brazilian top managers schedules}

\section{Betania Tanure*}

Pontifícia Universidade Católica de Minas Gerais - PUC-MG, Belo Horizonte, Minas Gerais, Brasil

\section{Antonio Carvalho Neto**}

Pontifícia Universidade Católica de Minas Gerais - PUC-MG, Belo Horizonte, Minas Gerais, Brasil

\section{Carolina Maria Mota Santos***}

Pontifícia Universidade Católica de Minas Gerais - PUC-MG, Betim, Minas Gerais, Brasil

\section{Roberto Patrus****}

Pontifícia Universidade Católica de Minas Gerais - PUC-MG, Belo Horizonte, Minas Gerais, Brasil

\begin{abstract}
RESUMO
O objetivo deste artigo é verificar a percepção do tempo para os executivos brasileiros e a sua relação com o estresse. Os dados da pesquisa, que conjugou estratégia quantitativa e qualitativa, demonstram que o estresse está diretamente relacionado com o uso do tempo. Há diferença estatisticamente significativa quanto ao grau de satisfação no trabalho entre as pessoas que trabalham de 8 a 9 horas e as que trabalham 12 horas ou mais. Nesse último caso, a freqüência de sintomas de estresse é maior. 0 tempo dos altos executivos é abordado como algo autônomo, abstrato, independente, tal qual a concepção de tempo associada à concepção mecanicista da natureza. Não por acaso, o estresse já foi caracterizado como uma doença do tempo.
\end{abstract}

Palavras-chave: executivos, estresse, tempo.

\section{ABSTRACT}

The aim of this article is to verify the perception of Brazilian executives about the relation between time and stress. The research that conjugated quantitative and qualitative data shows that stress is directly related with time schedule. There is significant statistical difference as to the satisfaction level at work among people that work from 8 to 9 hours daily and those who work 12 hours or more. In this last case the stress symptoms are larger. Top executives approach time as something autonomous, abstract, independent, associating time to the mechanical conception of nature. Not by chance, stress was already characterized as a disease of time. 
Keywords: executives, stress, time.

\section{Introdução}

O estresse já foi caracterizado como a doença do tempo (Pena, 2002). Associado pelo senso comum ao deus Crono, da mitologia grega, o tempo tudo constrói, tudo destrói. No mito grego, Crono destruía a sua própria criação ao devorar os próprios filhos, para o desespero de sua mulher, Réia. O tempo possibilita ao ser humano a criação da sua história. O estresse, como doença do tempo, destrói a qualidade de vida do indivíduo, que se vê "sem tempo" para realizar suas responsabilidades e desenvolver suas relações afetivas. A pressa é "a alma dos nossos negócios", canta Paulinho da Viola. Andamos acelerados, a 100 quilômetros por hora, como na canção.

Toda concepção de tempo está relacionada com uma determinada concepção de mundo. Na concepção de mundo contemplado, própria do período clássico, greco-romano, em que a medida do tempo é feita pela natureza, o estresse no trabalho não poderia ser associado ao tempo. É na concepção de um mundo fabricado, própria do período moderno, em que a medida do tempo é feita por um artefato que mede as horas artificialmente, que tempo e estresse se relacionam de modo inextrincável, como no caso dos executivos, alvo do presente estudo.

Além dessa introdução, o trabalho tem mais quatro seções. 0 referencial teórico está dividido em duas partes. A primeira aborda o tempo em suas duas concepções, a natural e a moderna. Ambas são relacionadas com a forma de mensuração e de percepção do tempo, respectivamente, com o relógio de sol e com o relógio mecânico. A segunda parte do referencial teórico traz a descrição das tipologias básicas de estresse, a partir de uma leitura cuidadosa de autores como Selye (1959; 1965; 1974), Albrecht (1990), Cooper (1988) e autores brasileiros como Moraes, Pereira, Lopes, Rocha, Ferreira e Portes, (2001), Couto (1987) e Lipp (1996). A terceira seção do texto aborda os procedimentos metodológicos da pesquisa empírica. A estratégia de investigação recaiu sobre o método misto qualitativoquantitativo, como explica Creswell (2003), onde um complementa o outro. Dessa pesquisa, foram selecionados os dados quantitativos e qualitativos que associam o estresse ao tempo, como o objetivo de verificar a percepção do tempo para o público-alvo pesquisado e a sua relação com o estresse. A quarta seção traz os resultados da pesquisa empírica, no tocante aos dados que cruzam o estresse e 0 tempo de trabalho. A quinta e última seção trata das considerações finais, onde se procura relacionar a reflexão teórica sobre o tempo com os dados da pesquisa sobre o estresse. 
Sem deixar de considerar outros fatores que podem desencadear desordens psicossomáticas, o corte para a apresentação dos dados foi o tema "tempo". A compreensão moderna de estresse está relacionada com a concepção de um tempo autônomo, artificial, que mede as horas independentemente da natureza. Embora o alto executivo aparentemente tenha muito mais controle sobre a sua agenda do que a maioria dos trabalhadores da base da hierarquia organizacional, ele se vê refém de condicionantes do macro ambiente empresarial, da roda viva dos negócios. O tempo lhe é autônomo, visto como uma roda viva, uma entidade impessoal e abstrata.

\section{Referencial teórico}

\subsection{Duas concepções de tempo, duas formas de medi-lo}

A mensuração do tempo é feita pelo relógio. A palavra relógio tem sua origem etimológica na palavra grega horológion, composta por hora, horas, e por lego, dizer. Literalmente, significa o que diz as horas. Em latim, se diz horologiu, em italiano, orologio, em francês, horloge, e em espanhol, reloj. Para cada concepção de mundo, temos uma forma diferente de medir o tempo, ou seja, um tipo de relógio. A concepção contemplativa do mundo corresponde ao relógio de sol. A concepção mecanicista de mundo, moderna, corresponde ao relógio mecânico.

\subsubsection{A concepção contemplativa de mundo e o relógio de sol}

Os astrônomos foram os primeiros homens a se ocuparem da medição do tempo, usando o movimento regular dos astros. Primitivamente, o homem dividiu o tempo em noite e dia. O passo seguinte foi o fracionamento do período diurno em certo número de partes, que podemos hoje chamar de horas, e isso aconteceu graças ao movimento da sombra dos corpos iluminados pelo Sol (Barnnet, 1998).

O relógio de sol não pode ser entendido como um relógio na concepção moderna do termo, pois não era um artefato imprescindível para o homem antigo. Os calendários com anos, meses e semanas foram desenvolvidos bem antes do que as horas. Para uma cultura então essencialmente agrária, o que interessava eram as estações do ano. Não havia necessidade de contar as horas, e sim conhecer as estações e a melhor época para o plantio e para a colheita. Quando as horas começaram a ser medidas, apenas as horas do dia eram contadas. Por muitos séculos, não se mediu o tempo da noite. A noite era útil apenas para dormir, por isso não havia razão para tentar medir suas horas (Barnett, 1998:17). 
O primeiro relógio foi encontrado no Egito. Tratava-se de uma simples estaca presa ao chão, que indicava o tempo através do deslocamento da sombra do Sol. As sombras se deslocam para o oeste pela manhã, quando o Sol está no leste, e se movem para o leste durante a tarde, quando o Sol cruza em direção ao céu ocidental. Um outro relógio de sol, também egípcio, foi encontrado em 1500 a.C. É mais avançado que o anterior porque permite uma calibração das mudanças da sombra à medida que o sol fica mais alto no céu. Ao meio-dia, a direção do instrumento necessita ser mudada para continuar medindo as outras seis horas da tarde.

É importante ter em conta que as horas medidas pelos relógios de sol são temporárias, ou seja, não são as mesmas horas que usamos hoje para medir o tempo. Ainda que eles tenham condições de medir partes do dia - dia entendido como intervalo entre o nascer e o pôr do sol - isso não significa que as horas medidas antigamente tenham os sessenta minutos da hora de hoje. Nossas horas de hoje são as mesmas durante todo o ano, todas têm sessenta minutos. Mas, para os antigos, uma hora no verão era bem mais longa do que uma hora no inverno. De fato, apenas no Equador as horas seriam iguais. As horas do relógio de sol são horas temporárias, não uniformes, elas variam de acordo com a estação e o momento do dia.

Em essência, o relógio de sol é a esquematização de uma árvore que produz uma sombra e sua trajetória durante a passagem do dia. É um artefato que não transforma a natureza, apenas a reproduz. Aproxima-se do que Ortega y Gasset (1998) chama de instrumento, um prolongamento da natureza, pertinente ao estágio primitivo da técnica.

O relógio de sol preserva a intenção da Física aristotélica de não alterar a natureza. $\mathrm{O}$ homem obedece à natureza na medida em que é ela quem determina, (falando em termos anacrônicos, isto é, usando termos modernos que não seriam utilizados naquela época), a duração ou a quantidade de minutos de uma hora. O relógio de sol estuda o tempo em condições reais. Tão reais que quem determina a duração do dia são as estações do ano. O relógio de sol é um artifício, mas não tem função sem a natureza. Trata-se de um artifício que não pode abrir mão da natureza. É uma continuação dela.

Também o movimento no relógio de sol é natural. Não há nesse artefato um movimento sequer que seja movido por um empurrão ou arrastão, ou seja, pelo que Aristóteles chamou de movimento violento. O mundo devia ser contemplado, o homem deveria curvarse às leis da natureza. O homem antigo se adaptava à natureza, por isso o seu instrumento para medir o tempo teria de respeitar a natureza. O relógio de sol é um artefato que reproduz a natureza, ou, literalmente, acompanha o movimento do Sol. O tempo natural determinava suas atividades de trabalho na terra. O registro do tempo é um espelho (sombra) da natureza e o homem antigo 
obedecia às suas determinações. Ele ia se deitar assim que o Sol se punha no oeste e só se preparava para o trabalho ao amanhecer. 0 momento de trabalhar estava diretamente relacionado com a luz do dia. O pôr-do-sol determinava a hora de parar de trabalhar. A natureza era quem controlava a agenda do homem antigo. Nos dias frios de inverno, trabalhava por menos tempo e dormia um pouco mais.

A concepção de mundo subjacente ao relógio de sol é a de um mundo natural que deve ser contemplado. Para os antigos, não compete ao ser humano alterar a ordem da natureza. É o homem que deve se adaptar à natureza e não a natureza ao homem. Nessa perspectiva, não é o homem que determina o momento de trabalhar e o de descansar, mas a própria natureza, representada pelo movimento do sol ou pelo corpo que pede repouso.

A reflexão sobre o estresse no trabalho e sua associação com o tempo só é possível quando tempo é concebido como uma entidade autônoma, artificial, algo abstrato que existe por si mesmo. O estresse como doença do tempo não seria concebível se o tempo fosse pensado como no mundo contemplado dos antigos. Se as horas fossem temporárias, o executivo e o operário se adaptariam à natureza. É somente com a compreensão do tempo como entidade autônoma que o ser humano se vê obrigado a cumprir prazos, independentemente da temperatura fria ou escaldante. A concepção moderna de tempo é o que será visto a seguir.

\subsubsection{A concepção mecanicista de mundo e o relógio mecânico}

O relógio mecânico é um mecanismo de engrenagens dotadas de algum elemento regulador que contém o movimento do sistema, mantendo sua rotação em um ritmo simétrico. A primazia da criação de um escape mecânico é atribuída ao povo da China. Seu inventor seria o monge budista, notável matemático e astrônomo de seu tempo, I-Hsing (682-727). Os relógios mecânicos, desde o início até fins da Idade Média (1300-1450), foram festejados de tal forma que foram considerados como símbolos do equilíbrio, da sabedoria e da virtude. Grande parte dos relógios construídos nesse período, ou mesmo posteriormente, apresentavam figuras e desenhos alusivos a essas qualidades que o homem deveria possuir (Barnett, 1999).

O relógio mecânico é formado por um conjunto de peças combinadas entre si que funcionam juntas com a finalidade de medir as horas, minutos e segundos. O relógio usa uma peça de metal flexível, a mola principal, que é enrolada e liberada. O tempo indicado no mostrador pelos ponteiros é o tanto que a mola principal se desenrolou. O movimento dos ponteiros é causado pelo giro das rodas que movem umas as outras, a partir da energia fornecida pela mola principal. 
O relógio mecânico pressupõe uma concepção mecanicista do mundo, cujo principal articulador foi o filósofo francês Descartes (1596-1560), pai do racionalismo moderno. Para Descartes, o comportamento da natureza tem como modelo a máquina. O mundo não é como um organismo biológico (como imaginava Aristóteles), mas como uma máquina (Descartes, 1989). O relógio mecânico é um produto do homem, não é natural, é um artefato, é uma máquina. Nele não há movimento espontâneo, gerado pela natureza. Ao contrário do relógio de sol, a marcação das horas é artificial. Mesmo com o tempo frio e escuro pela manhã, o relógio mecânico vai marcar a mesma hora para que se inicie a jornada de trabalho. O trabalhador moderno vai acordar mesmo que o sol não tenha ainda nascido.

As horas do relógio mecânico não são temporárias. São as mesmas em todas as estações, têm sempre 60 minutos. "O relógio mecânico transformou o tempo e os ritmos da natureza em algo abstrato e autônomo, uma entidade em si mesma" (Barnett, 1999:56). O tempo se liberou dos eventos da natureza e "sua divisão em unidades matemáticas iguais foi o momento anterior a este mundo de ciência" (Barnett, 1999:59). O tempo compreendido como uma entidade criou a crença da independência do mundo matematicamente mensurável: o mundo da ciência.

Para Descartes, a matéria tem extensão geométrica. $O$ mundo é cheio, pois não há espaço vazio. Se há movimento no mundo, quando uma matéria se move ela provoca movimento em outra matéria, que provoca movimento em outra matéria, e assim sucessivamente. Compreender este movimento é conhecer as relações matemáticas e geométricas entre os corpos que se chocam (Descartes, 1989). O relógio mecânico é a mais perfeita metáfora dessa concepção da natureza, pois nele o movimento se sucede por meio do choque e de precisas disposições matemáticas e geométricas para a verificação correta das horas do dia e da noite.

0 relógio é a metáfora perfeita para descrever o mundo fabricado, o mundo moderno, ou seja, a concepção mecanicista do mundo que Descartes inaugura. Segundo Munford (1934), o relógio é o verdadeiro símbolo da era moderna industrial, e não a máquina a vapor. Percebemos a importância da imprensa, da eletricidade, do avião, mas nos esquecemos, em geral, "da suprema importância do relógio mecânico" (Munford, 1934). Segundo Landes (1983), esses relógios foram, como são os computadores hoje, a sensação tecnológica de seu tempo. Internamente, representam o mundo mecanicista. Externamente, medem o tempo. E não param.

\subsection{Estresse: conceitos e tipologias básicas}

Estresse é uma palavra derivada do latim stringere, que significa tração apertada, ou seja, "espremer". Dada a raiz etimológica, não 
parece coincidência a relação com o tempo "espremido" de quem se vê estressado. Inicialmente, definições de pressão e carga usadas na medicina e na engenharia influenciaram a percepção do estresse e de como medi-lo (Cooper, Cooper \& Eaker, 1988; Arnold, Robertson \& Cooper, 1995). Segundo Lipp (1996), por volta do século XVII, os estudos na área de engenharia apontavam que, para a escolha do material para construção de pontes e outras estruturas, as características das cargas tinham que ser levadas em conta. Daí se origina a idéia de que as pessoas suportam carga emocional, ou que o trabalho pode ser mais ou menos pesado para algumas pessoas.

As pressões geradas pelas contínuas transformações atuais têm exigido cada vez mais dos indivíduos, seja em termos de responsabilidades com o trabalho, seja em sobrecarga adicional de tarefas, tornando os indivíduos mais vulneráveis às doenças psicossomáticas e orgânicas, dentro e fora das empresas (Moraes e Sicoli, 2004). Na década de 1970, Albrecht (1990) já destacava que o estresse, então uma doença nova e estranha, havia surgido na vida das pessoas de países altamente industrializados e estava trazendo um elevado custo em termos de saúde e bem-estar emocional. Para esse autor, não se trata de uma doença propriamente dita, mas uma condição de descontrole de uma função fisiológica normal do corpo humano.

Selye (1959; 1965), completando o conceito de estresse, relaciona uma série de idéias errôneas e distorcidas existentes sobre o termo. O autor afirma que o termo estresse era aplicado de forma tão diversa e confusa que seria mais fácil começar por estabelecer o que não é estresse. Fraser (1983) também aponta a dificuldade em definir o termo estresse. Ao falar sobre o conceito, usa estresse e pressão como sinônimos e afirma que o estresse é subjetivo e associado à condições emocionais e psicológicas. De fato, o indivíduo estressado se vê pressionado por uma "roda viva", percebendo o tempo como insuficiente para as demandas de terceiros e autoimpostas. $O$ estresse pode ser definido como um "estado manifestado por uma síndrome específica, constituída por todas as alterações nãoespecíficas produzidas num sistema biológico". (Selye, 1965, p.64). Apesar de associado a uma falta de compensação do organismo, o estresse pode indicar equilíbrio. No que se refere às conseqüências positivas e negativas do estresse, Selye (1974) utiliza os termos distresse e eustresse. O eustresse é o estresse da realização, é uma resposta positiva do organismo a um estímulo. Podemos ver com bons olhos certas experiências e situações de estresse por causa dos sentimentos positivos que temos diante delas. O eustresse que acompanha estas experiências é uma parte natural de superação eficaz de desafios, como os de um cargo administrativo ou de qualquer outro trabalho profissional (Albrecht, 1990). Rio (1995) acrescenta que no eustresse há o predomínio da emoção da alegria, 
podendo haver momentos de ansiedade discreta, criativa. Não é raro, em nossa experiência, encontrar depoimentos de altos executivos que afirmam adorar a "adrenalina" que o trabalho produz neles, mas que se queixam da falta de tempo, da sensação de dívida permanente, da sensação de que nunca havia tempo suficiente para "zerar" as demandas do trabalho.

Inversamente, o distresse é um fenômeno negativo que pode gerar danos ao organismo. Há predominância das emoções de ansiedade destrutiva, medo, tristeza e raiva (Rio, 1995). Albrecht (1990) acrescenta que o grande inimigo da saúde humana não é a crise ocupacional, a situação perigosa ou, ainda, a perturbação emocional. O inimigo é o distresse, o estado prolongado e constante de preocupação, ansiedade e alerta do qual o indivíduo parece não poder escapar. Apesar do perigo que o excesso de estresse possa trazer para a saúde e o bem-estar, isso não significa que se deva eliminar todo o estresse, pois até a felicidade e a alegria causam o mesmo (Albrecht, 1990). As reações de estresse são naturais e necessárias para a vida, mas, sob algumas circunstâncias, elas podem se tornar prejudiciais ao funcionamento do indivíduo (Limongi-França; Rodrigues, 1996).

O distresse tem assumido o status de doença. Provavelmente, uma das razões do estado de distresse acontecer com maior freqüência neste século é haver maior quantidade de estressores ou mudanças do que suporta a capacidade humana (Moraes \& Kilimnik, 1992 ; Moraes et al., 2001). Há quase três décadas, Goldberg (1980) já mencionava a sobrecarga de trabalho, excessiva responsabilidade, exigências conflitantes no trabalho e ambigüidade de papéis como origens de distúrbios devidos ao estresse. Todos esses fatores são acompanhados por uma exigência de curto prazo.

Atualmente, o enorme grau de superação demandado pelo mundo dos negócios, a busca incessante por melhores resultados e maior participação no mercado fazem com que as empresas procurem contar com espécies de super-heróis, buscando profissionais dotados de competências cada vez mais variadas e sofisticadas, num movimento de deificação da gerência (Carvalho Neto, Tanure, Santos $\&$ Lima, 2012). Certamente este quadro é o que mais favorece uma tendência ao distresse (Sant'anna, Moraes \& Kilimnik, 2003).

Os executivos estão, mais do que nunca, lidando com um mundo em transição. Previsibilidade e controle, importantes proteções contra o estresse causador de doenças, parecem cada vez mais inalcançáveis. Com o aumento do estresse, os colapsos da saúde do gerente representam agora uma verdadeira ameaça à organização e às próprias pessoas. (Goldberg, 1980; Albrecht, 1990; Moraes \& Kilimnik, 1992).

Algumas mudanças no mundo do trabalho estão acontecendo numa velocidade acelerada, pondo a capacidade de adaptação das pessoas 
à prova em todos os aspectos (físico, psicológico, emocional e espiritual). Esta velocidade destrói a sensação de estabilidade. (Moraes \& Kilimnik,1992). "Tudo isso quer dizer que devemos procurar não mudar?", pergunta Goldberg (1980, p.44). Não, as mudanças são essenciais à vida; o que o ser humano deve fazer é procurar regulá-las, pelo menos as que estão sob seu controle. Entretanto, a sensação de falta de governabilidade para mudar essa pressão excessiva do trabalho sobre as outras dimensões da vida é muito sentida pelos executivos (Tanure, Carvalho Neto \& Andrade, 2007).

Apesar de o estresse ser um fenômeno comum a todas as ocupações, ele pode ser mais facilmente identificado em alguns grupos específicos, em que as fontes de pressão desses postos de trabalho são mais altas, se comparadas a muitas outras profissões (Mendes, 2000; Mendes \& Moraes, 2001; Metzker, Moraes \& Zille, 2012).

O distresse é muito mais alto nos executivos que chegaram ao alto escalão das maiores empresas (Tanure et al.,2007). Algumas profissões tendem a ser mais estressantes em função de suas características intrínsecas (Zille, Moraes, Marques e Silva, 2001; Metzker, Moraes \& Zille, 2012). Este parece ser o caso dos executivos de alto escalão, público-alvo da pesquisa contemplada neste artigo. Um executivo, para chegar até a cúpula e lá se manter, precisa percorrer um caminho repleto de pressões que criam estresse diariamente. Esse estresse pode ser excessivo e crônico, e pode gerar problemas de saúde que acabam por prejudicar a carreira do executivo. Além disso, muitos vivem em estado de tensão e, mesmo quando podem relaxar, têm dificuldade de fazê-lo (Couto, 1987; Lipp, 1996).

Uma das pressões sofridas pelo alto executivo se relaciona com o tempo. São as demandas de curto prazo, a exigência de pontualidade, os compromissos que se interpõem, as viagens, que, muitas vezes, o fazem trabalhar dobrado antes dela (para poder sair da empresa), e depois (para colocar a agenda em dia). A compreensão moderna de estresse está relacionada com a concepção de um tempo autônomo, artificial, que mede as horas independentemente da natureza. Embora o alto executivo aparentemente tenha muito mais controle sobre a sua agenda do que a maioria dos trabalhadores da base da hierarquia organizacional, ele se vê refém de condicionantes do macro ambiente empresarial, da roda viva dos negócios. O tempo lhe é autônomo, visto como uma roda viva, uma entidade impessoal e abstrata. Como a agenda de trabalho tem datas marcadas, o executivo adia as demandas afetivas. Sua sensação é que Ihe chega uma "roda viva, e carrega a saudade prá lá", como na canção de Chico Buarque. Por mais que o executivo queira priorizar suas demandas afetivas, sua saudade, ele não se sente com o controle sobre o seu tempo. 


\section{Metodologia}

Este artigo baseia-se em pesquisa de caráter descritivo, realizada com executivos brasileiros de alto escalão. A estratégia de pesquisa recaiu sobre o método misto qualitativo-quantitativo, como explica Creswell (2003), onde um complementa o outro. A pesquisa qualitativa foi a primeira a ser realizada. Dessa pesquisa, foram selecionados os dados quantitativos e qualitativos que associam o estresse ao tempo, como o objetivo de verificar a percepção do tempo para o público-alvo pesquisado e a sua relação com o estresse.

O universo da amostra constituiu-se dos executivos das quinhentas maiores empresas situadas no Brasil. Considerando a representatividade dos executivos dessas grandes empresas, houve a possibilidade de se realizar uma aproximação pela amostragem probabilística aleatória simples, que se caracteriza pelo fato de cada componente da população ter probabilidade conhecida, diferente de zero, e idêntica à dos outros componentes, de ser selecionado para fazer parte da amostra (Mattar, 1999).

Os dados quantitativos foram coletados por meio de questionário fechado via internet para executivos. O questionário utilizou algumas questões de múltipla escolha e outras em escala tipo Likert. O uso da escala tipo Likert de 1 a 7 possibilitou a obtenção de uma graduação quantificada das percepções dos entrevistados, permitindo, assim, o cálculo de índices de cada uma delas (Marconi \& Lakatos, 1999). Através de escala Likert avaliou-se o que se denominou de "Índice Global de Satisfação" dos executivos, composto por duas grandes dimensões que abarcaram o conjunto de 18 variáveis:

- dimensão relacionada a fatores pessoais: composta por variáveis relativas à satisfação com filhos, familiares, parceiro amoroso, amigos, alimentação e saúde;

- dimensão relacionada a fatores relativos à empresa: composta por variáveis como relações com pares, chefes, subordinados, nível de cobrança por resultados e sistema de recompensas.

Através também de escala Likert de 1 a 7 avaliou-se o que se denominou de "Índice Global de Sensações/atitudes" dos executivos, composto por 27 variáveis relativas à sensação em relação a fatores relacionados ao estresse, como ansiedade, dor de cabeça, fadiga, falta de sono, irritabilidade, desânimo, diminuição do interesse sexual, tremores, dormência, medos, hábitos alimentares, consumo de bebidas alcoólicas, fumo, dentre outros.

Foram recebidos 965 questionários considerados válidos dos executivos que chegaram ao topo da hierarquia organizacional 
(presidentes, vice-presidentes/diretores e gerentes de terceiro nível) de 344 empresas.

Dado o número extenso de variáveis e o tamanho significativo da amostra, utilizaram-se as seguintes ferramentas estatísticas para proceder a um rigoroso tratamento dos dados: Teste Qui-Quadrado; ANOVA (a um fator); Análise de Regressão Linear; Análise Fatorial.

$\mathrm{Na}$ parte qualitativa, foram entrevistados 263 executivos(as) de 10 grandes empresas (indústria e serviços) nas mesmas posições hierárquicas da pesquisa quantitativa descrita acima, através de roteiros semi-estruturados, sendo 96 pessoas entrevistadas individualmente e 167 por meio de grupos de foco.

\section{Apresentação e Análise dos resultados}

Foram descritos a seguir os dados da pesquisa que se relacionam com o tempo. Com relação às horas de trabalho por dia útil, mais da metade dos entrevistados $(53,2 \%)$ diz trabalhar de 10 a 11 horas e quase um terço $(28,6 \%)$ diz trabalhar 12 horas ou mais (Tabela 1 ).

Tabela 1

Horas de trabalho por dia útil

\begin{tabular}{|c|c|c|c|c|}
\hline $\begin{array}{l}\text { Horas de trabalho } \\
\text { por dia útil }\end{array}$ & Freqüência & Porcentagem & $\begin{array}{l}\text { Porcentagem } \\
\text { Válida }\end{array}$ & $\begin{array}{c}\text { Porcentagem } \\
\text { Acumulada }\end{array}$ \\
\hline de 8 a $9 \mathrm{~h}$ & 176 & 18,2 & 18,3 & 18,3 \\
\hline $\begin{array}{l}\text { de } 10 \text { a } \\
11 \mathrm{~h}\end{array}$ & 512 & 53,1 & 53,2 & 71,4 \\
\hline $\begin{array}{l}\text { de } 12 \text { a } \\
13 \mathrm{~h}\end{array}$ & 233 & 24,1 & 24,2 & 95,6 \\
\hline $\begin{array}{l}\text { de } 14 \text { a } \\
15 \mathrm{~h}\end{array}$ & 38 & 3,9 & 3,9 & 99,6 \\
\hline $\begin{array}{l}\text { Mais de } \\
16 \mathrm{~h}\end{array}$ & 4 & 0,4 & 0,4 & 100, \\
\hline Total & 963 & 99,8 & 100, & \\
\hline $\begin{array}{l}\text { Não } \\
\text { respondeu }\end{array}$ & 2 & 0,2 & & \\
\hline Total & 965 & 100, & & \\
\hline
\end{tabular}

Fonte: Dados da pesquisa

O depoimento de um executivo ilustra bem esta situação:

“Todo dia saio com a sensação de que deixo coisa para trás. Difícil é gerenciar o tempo: não depende só de mim. Chego da empresa e continuo trabalhando em casa. Quando chego meu filho está dormindo". 
Dados da pesquisa qualitativa indicaram que os respondentes não computaram, ao responder o questionário, as horas de viagens, almoços e jantares de negócios, coquetéis de trabalho, reuniões de madrugada em viva voz com executivos de outros países de fuso horário diferente e leitura de e-mails em casa. Os dados quantitativos indicam as horas que os executivos estão na empresa, isto é, o intervalo entre a hora que entram para trabalhar e a hora que vão para casa. Portanto, a jornada indicada na pesquisa quantitativa parece ser bem maior.

Tabela 2

Horas de trabalho por dia útil x cargo

\begin{tabular}{|c|c|c|c|c|c|c|}
\hline \multirow[b]{2}{*}{ Cargo } & & & \multicolumn{3}{|c|}{$\begin{array}{c}\text { Horas de trabalho por dia } \\
\text { útil }\end{array}$} & \multirow[t]{2}{*}{ Total } \\
\hline & & & $\begin{array}{c}\text { de } 8 \text { a } \\
9 h\end{array}$ & $\begin{array}{c}\text { de } 10 \text { a } \\
11 \mathrm{~h} \\
\end{array}$ & $\begin{array}{l}12 \mathrm{ou} \\
\text { mais }\end{array}$ & \\
\hline & \multirow[t]{2}{*}{ Presidência } & Freqüência & 2 & 22 & 12 & 36 \\
\hline & & $\%$ Cargo & $5,6 \%$ & $61,1 \%$ & $33,3 \%$ & $100,0 \%$ \\
\hline & \multirow[t]{2}{*}{$\begin{array}{l}\text { Vice- } \\
\text { presidência } \\
\text { / Diretoria }\end{array}$} & Freqüência & 28 & 107 & 86 & 221 \\
\hline & & $\%$ Cargo & $12,7 \%$ & $48,4 \%$ & $38,9 \%$ & $100,0 \%$ \\
\hline & \multirow[t]{2}{*}{ Gerência } & Freqüência & 146 & 383 & 177 & 706 \\
\hline & & \% Cargo & $20,7 \%$ & $54,2 \%$ & $25,1 \%$ & $100,0 \%$ \\
\hline \multirow[t]{2}{*}{ Total } & & Freqüência & 176 & 512 & 275 & 963 \\
\hline & & \% Cargo & $18,3 \%$ & $53,2 \%$ & $28,6 \%$ & $100,0 \%$ \\
\hline
\end{tabular}

Qui-quadrado: P-valor $=0,000$

Fonte: Dados da pesquisa

Ao se cruzarem as horas de trabalho com o cargo ocupado pelo respondente, observou-se que o percentual de pessoas que trabalham mais de 10 horas é maior na Presidência do que nos demais cargos $(94,4 \%)$. Em contrapartida, a maior porcentagem de entrevistados que trabalham de 8 a 9 horas ocorre na gerência (Tabela 2).

A tabela 3 a seguir apresenta a satisfação média dos entrevistados, distribuída pelo tempo de trabalho por dia útil. Há diferença significativa com relação a horas de trabalho por dia útil. Dentre as questões que apresentaram diferenças significativas, as pessoas que trabalham de 8 a 9 horas são as mais satisfeitas, já as que trabalham 12 horas ou mais são as menos satisfeitas com estes itens. Esse dado demonstra objetivamente que, dentro dos limites de horas pesquisados, o nível de satisfação é inversamente proporcional ao número de horas trabalhadas por dia útil.

O depoimento de um executivo entrevistado expressa o incômodo pelo excesso de trabalho: 
"Ninguém exige que eu trabalhe 12 horas, mas as metas tão desafiadoras não dão opção. O nível de auto-exigência é muito alto, e mais ainda nos cargos mais altos. O que desagrada é fazer retrabalho por falta de planejamento dos outros".

Tabela 3

Satisfação $\mathrm{x}$ horas de trabalho por dia útil

\begin{tabular}{|c|c|c|c|}
\hline I tens de satisfação & $\begin{array}{c}\text { De } 8 \\
\text { a } \\
9 \text { hs }\end{array}$ & $\begin{array}{c}\text { De } \\
10 \text { a } \\
11 \text { hs }\end{array}$ & $\begin{array}{l}\text { 12hs } \\
\text { ou } \\
\text { mais }\end{array}$ \\
\hline Q13.1 Satisfação com a saúde & $5,21^{a}$ & $\begin{array}{c}4,86^{b} \\
\downarrow\end{array}$ & $4,67^{\mathrm{b}} \downarrow$ \\
\hline Q13.2 Satisfação com o número de amigos que tem & $\underset{\mathrm{a} \uparrow}{4,92}$ & 4,76 & $4,56^{\mathrm{b} \downarrow}$ \\
\hline $\begin{array}{l}\text { Q13.4 Satisfação com o nível de cobranças por resultados } \\
\text { na empresa }\end{array}$ & $\begin{array}{c}4,51 \\
a \uparrow\end{array}$ & $\begin{array}{c}4,47 \\
\mathrm{a} \uparrow\end{array}$ & $4,27^{\mathrm{b} \downarrow}$ \\
\hline Q13.5 Satisfação com a relação com outros familiares & $\begin{array}{c}5,14 \\
\mathrm{a} \uparrow\end{array}$ & $4,89^{b}$ & $4,62^{\complement} \downarrow$ \\
\hline $\begin{array}{l}\text { Q13.10 Satisfação com a factibilidade das metas } \\
\text { estabelecidas pela empresa }\end{array}$ & $\begin{array}{c}4,57 \\
\mathrm{a} \uparrow\end{array}$ & $\underset{\mathrm{a} \uparrow}{4,56}$ & $4,28^{\mathrm{b}} \downarrow$ \\
\hline Q13.12 Satisfação com a relação com os filhos & $\begin{array}{c}5,83 \\
\mathrm{a} \uparrow\end{array}$ & $\begin{array}{c}5,57 \\
b \downarrow\end{array}$ & $5,41^{b} \downarrow$ \\
\hline Q13.13 Satisfação em relação à carga de trabalho que tem & $\begin{array}{c}4,82 \\
\mathrm{a} \uparrow\end{array}$ & $\underset{b}{4,22}$ & $3,55^{\mathrm{c} \downarrow}$ \\
\hline Q13.14 Satisfação com seus hábitos alimentares & $\begin{array}{c}4,74 \\
\mathrm{a} \uparrow\end{array}$ & $\underset{b}{4,27}$ & $3,90^{\mathrm{c} \downarrow}$ \\
\hline Q13.18 Satisfação com a convivência com os amigos & $\begin{array}{c}4,86 \\
\mathrm{a} \uparrow \\
\end{array}$ & $\underset{\mathrm{b}}{4,59}$ & $4,25^{\mathrm{c} \downarrow}$ \\
\hline $\begin{array}{l}\downarrow \text { Média significativamente menor que as outras categorias } \\
\uparrow \text { Média significativamente maior que as outras categorias } \\
\text { Escala de satisfação: } 1 \text { - Extremamente Insatisfeito(a) } \\
7 \text { - Extremamente satisfeito(a) }\end{array}$ & $\begin{array}{l}5,05) \\
05)\end{array}$ & & \\
\hline
\end{tabular}

Valores que possuem a mesma letra sobrescrita são estatisticamente semelhantes.

Fonte: Dados da pesquisa

A análise da freqüência média de sensações dos entrevistados em relação às horas de trabalho revelou que há diferença significativa com relação a horas de trabalho por dia útil (ver tabela 4). As pessoas que trabalham de 8 a 9 horas por dia útil apresentam sintomas de estresse com menos freqüência que as demais. Em contrapartida, os indivíduos que trabalham 12 horas ou mais apresentam sintomas relacionados ao estresse com maior freqüência. O depoimento de um executivo entrevistado exemplifica alguns sintomas biológicos do estresse:

"Já fui workaholic. Caiu a ficha quando a saúde abalou: a primeira crise de estresse foi há 8 anos. Eu estava viciado (no trabalho). Tive hérnia de hiato, baixa resistência, colesterol 
Betania Tanure, Antonio Carvalho Neto, Carolina Maria Mota Santos, Roberto Patrus Estresse, Doença do Tempo: um estudo sobre o uso do tempo pelos executivos brasileiros

alto. Repensei e comecei a cuidar da alimentação, planejar o tempo, fazer atividade física e parei de fumar."

Tabela 4

Horas de trabalho por dia útil $x$ Estresse

\begin{tabular}{|c|c|c|c|}
\hline Sensações/ atitudes & $\begin{array}{l}\text { De } 8 \\
\text { a } \\
9 \text { hs }\end{array}$ & $\begin{array}{l}\text { De } \\
10 \text { a } \\
11 \text { hs }\end{array}$ & $\begin{array}{l}\text { 12hs } \\
\text { ou } \\
\text { mais }\end{array}$ \\
\hline Q20.4 Fadiga. & $\begin{array}{l}3,23 \\
\quad \downarrow\end{array}$ & $\underset{b}{3,56}$ & $3,87^{\mathrm{a} \uparrow}$ \\
\hline $\begin{array}{l}\text { Q20.5 Se alimenta com freqüência maior ou em maior } \\
\text { quantidade do que o usual. }\end{array}$ & $\begin{array}{c}2,93 \\
b \downarrow\end{array}$ & $\begin{array}{c}3,30 \\
\mathrm{a} \uparrow\end{array}$ & $3,51^{\mathrm{a} \uparrow}$ \\
\hline Q20.6 Diminuição do interesse sexual. & $\begin{array}{c}2,68 \\
\mathrm{~b} \downarrow\end{array}$ & $\begin{array}{c}2,94 \\
a \uparrow\end{array}$ & $3,05^{\mathrm{a} \uparrow}$ \\
\hline Q20.7 Sensação de fôlego curto ou de falta de ar. & $\begin{array}{c}2,11 \\
\subset \downarrow\end{array}$ & $\begin{array}{c}2,38 \\
b\end{array}$ & $2,72^{\mathrm{a} \uparrow}$ \\
\hline Q20.9 Tremores musculares (Ex.: olhos, boca, mãos). & $\begin{array}{c}1,90 \\
\mathrm{~b} \downarrow\end{array}$ & $\begin{array}{c}2,11 \\
\mathrm{~b} \downarrow\end{array}$ & $2,35^{\mathrm{a} \uparrow}$ \\
\hline Q20.11 Tomar pílulas para dormir & $\begin{array}{c}1,22 \\
b \downarrow\end{array}$ & 1,28 & $1,43^{\mathrm{a} \uparrow}$ \\
\hline $\begin{array}{l}\text { Q20.12 Sensação de desânimo pela manhã, ao } \\
\text { levantar. }\end{array}$ & $\begin{array}{c}2,54 \\
\mathrm{~b} \downarrow\end{array}$ & $\begin{array}{c}2,91 \\
a \uparrow\end{array}$ & $3,05^{\mathrm{a} \uparrow}$ \\
\hline $\begin{array}{l}\text { Q20.13 Tendência a suar em excesso ou sensação de } \\
\text { sentir seu coração batendo mais forte. }\end{array}$ & $\begin{array}{c}1,97 \\
b \downarrow\end{array}$ & 2,17 & $2,38^{a} \uparrow$ \\
\hline Q20.14 Nervosismo. & $\begin{array}{c}2,98 \\
\mathrm{~b} \downarrow\end{array}$ & $\begin{array}{c}3,25 \\
a \uparrow\end{array}$ & $3,49^{\mathrm{a} \uparrow}$ \\
\hline Q20.15 Angústia & $\begin{array}{c}2,91 \\
b \downarrow\end{array}$ & 3,10 & $3,29{ }^{a} \uparrow$ \\
\hline Q20.16 Ansiedade & $\begin{array}{c}3,59 \\
\mathrm{~b} \downarrow\end{array}$ & $\begin{array}{c}3,87 \\
a \uparrow\end{array}$ & $4,05^{\mathrm{a} \uparrow}$ \\
\hline $\begin{array}{l}\text { Q20.17 Ímpetos de raiva (no trabalho, em casa, no } \\
\text { trânsito). }\end{array}$ & $\begin{array}{c}2,99 \\
\mathrm{~b} \downarrow\end{array}$ & 3,21 & $3,40^{\mathrm{a} \uparrow}$ \\
\hline Q20.19 I rritabilidade fácil. & $\begin{array}{l}2,90 \\
\quad \downarrow\end{array}$ & $3,15^{b}$ & $3,46^{\mathrm{a} \uparrow}$ \\
\hline Q20.24 Dor discreta no peito & $\begin{array}{c}1,56 \\
\mathrm{~b} \downarrow\end{array}$ & $\begin{array}{c}1,70 \\
\mathrm{a}, \mathrm{b}\end{array}$ & $1,85^{\mathrm{a} \uparrow}$ \\
\hline Q20.27 Insatisfação com as relações afetivas & $\begin{array}{c}2,53 \\
\mathrm{~b} \downarrow\end{array}$ & $\begin{array}{c}2,70 \\
b \downarrow\end{array}$ & $2,99{ }^{\mathrm{a} \uparrow}$ \\
\hline \multicolumn{4}{|c|}{$\begin{array}{l}\downarrow \text { Média significativamente menor que as outras categorias }(p \leq, 05) \\
\uparrow \text { Média significativamente maior que as outras categorias }(p \leq, 05) \\
\text { Escala de Freqüência: } 1 \text { - Nunca } \quad 7 \text { - Sempre }\end{array}$} \\
\hline
\end{tabular}

Fonte: Dados da pesquisa

O relato acima oferece alguma luz sobre o estresse dos executivos. 0 diretor relata que, depois de uma crise de estresse, ele foi capaz de planejar o tempo e modificar seu comportamento diante do trabalho. Esse dado revela que, de alguma forma, é possível administrar o próprio tempo e trabalhar com mais saúde. A roda viva do trabalho deixa de ser um condicionante todo poderoso a determinar 0 
comportamento dos executivos. Muitos executivos revelaram que a vida corrida do trabalho é prazerosa. Permite-lhes ascensão profissional no curto prazo, reconhecimento profissional e uma atmosfera de poder, de estar participando de tudo. De algum modo, está aí a origem do "vício" de trabalhar.

A tabela 5 mostra que os altos executivos tendem a atender telefone celular ou responder e-mails relacionados ao trabalho, fora do horário normal de trabalho, com mesma ou maior freqüência com que trabalha nos fins de semana.

Conforme um executivo entrevistado:

“Coloco os e-mails em dia até 23 horas. O celular fica 24 horas no ar. Tem gente que desliga no sábado, eu não dou conta, não quero que alguma coisa fuja de controle, vou me culpar. Chefe liga sábado e domingo, às vezes é rápido, liga às 21 horas, 22 horas."

A tabela 6 (mais abaixo) apresenta a distribuição média de tempo com a vida profissional em que há diferença significativa com relação aos aspectos pessoais e aspectos relativos à empresa. No que diz respeito ao sentimento em relação à distribuição de tempo, quanto maior é o percentual gasto com a vida profissional, menos satisfeitos estão tanto o executivo como o cônjuge (de acordo com a percepção do executivo) com esta distribuição.

Tabela 5

Trabalhar em finais de semana $x$ Fora do horário normal de trabalho

\begin{tabular}{|c|c|c|c|c|c|c|c|}
\hline \multirow{2}{*}{\multicolumn{2}{|c|}{$\begin{array}{l}\text { Atende celular ou responde e- } \\
\text { mails relacionados ao trabalho }\end{array}$}} & \multicolumn{5}{|c|}{ Trabalha em finais de semana } & \multirow[t]{2}{*}{ Total } \\
\hline & & Nunca & Raramente & $\begin{array}{c}\text { Às } \\
\text { vezes }\end{array}$ & $\begin{array}{c}\text { Frequentem } \\
\text { ente }\end{array}$ & Sempre & \\
\hline \multirow[t]{2}{*}{ Nunca } & Freqüência & 12 & 8 & 5 & 1 & 0 & 26 \\
\hline & $\%$ & $14,6 \%$ & $2,2 \%$ & $1,3 \%$ & $0,8 \%$ & $0,0 \%$ & $2,7 \%$ \\
\hline \multirow[t]{2}{*}{ Raramente } & Freqüência & 32 & 105 & 29 & 5 & 0 & 171 \\
\hline & $\%$ & $\begin{array}{c}39,0 \\
\%\end{array}$ & $29,2 \%$ & $7,7 \%$ & $4,2 \%$ &, $0 \%$ & $\begin{array}{c}17,9 \\
\%\end{array}$ \\
\hline \multirow[t]{2}{*}{ Às vezes } & Freqüência & 27 & 150 & 129 & 15 & 2 & 323 \\
\hline & $\%$ & $\begin{array}{c}32,9 \\
\%\end{array}$ & $41,7 \%$ & $\begin{array}{c}34,0 \\
\%\end{array}$ & $12,7 \%$ & $14,3 \%$ & $\begin{array}{c}33,9 \\
\%\end{array}$ \\
\hline \multirow[t]{2}{*}{$\begin{array}{l}\text { Frequentem } \\
\text { ente }\end{array}$} & Freqüência & 8 & 61 & 129 & 46 & 2 & 246 \\
\hline & $\%$ & $9,8 \%$ & $16,9 \%$ & $\begin{array}{c}34,0 \\
\%\end{array}$ & $39,0 \%$ & $14,3 \%$ & $\begin{array}{c}25,8 \\
\%\end{array}$ \\
\hline \multirow[t]{2}{*}{ Sempre } & Freqüência & 3 & 36 & 87 & 51 & 10 & 187 \\
\hline & $\%$ & $3,7 \%$ & $10,0 \%$ & $23,0 \%$ & $43,2 \%$ & $71,4 \%$ & $\begin{array}{c}19,6 \\
\%\end{array}$ \\
\hline Total & Freqüência & 82 & 360 & 379 & 118 & 14 & 953 \\
\hline
\end{tabular}


Betania Tanure, Antonio Carvalho Neto, Carolina Maria Mota Santos, Roberto Patrus Estresse, Doença do Tempo: um estudo sobre o uso do tempo pelos executivos brasileiros

\begin{tabular}{ccccccc}
$\%$ & $\begin{array}{c}100,0 \\
\%\end{array}$ & $100,0 \%$ & $\begin{array}{c}100,0 \\
\%\end{array}$ & $100,0 \%$ & $100,0 \%$ & $\begin{array}{c}100 \\
\%\end{array}$ \\
\hline
\end{tabular}

Kendall: P-valor $=0,000$

Fonte: Dados da pesquisa

A entrevista com um executivo expressa isso: "Chego às 06:30 na empresa e saiu às 22:30. Esposa chia, só ouço bronca."

Tabela 6

Distribuição de tempo com a vida profissional em que há diferença com relação aos aspectos pessoais e relativas à empresa

\begin{tabular}{|c|c|c|}
\hline Aspectos pessoais & & $\begin{array}{l}\text { Percentual médio de } \\
\text { tempo gasto com a } \\
\text { vida profissional } \\
\end{array}$ \\
\hline \multirow{5}{*}{$\begin{array}{l}\text { Sentimento com relação à } \\
\text { distribuição de tempo e } \\
\text { energia }\end{array}$} & $\begin{array}{l}\text { Muito insatisfeito } \\
\text { (a) }\end{array}$ & $76,63^{\mathrm{a}} \uparrow$ \\
\hline & Insatisfeito (a) & $71,26^{b}$ \\
\hline & $\begin{array}{l}\text { Nem satisfeito (a), } \\
\text { nem insatisfeito } \\
\text { (a) }\end{array}$ & $66,19^{c}$ \\
\hline & Satisfeito (a) & $63,11^{c}$ \\
\hline & Muito Satisfeito & $57,65^{d} \downarrow$ \\
\hline \multirow{5}{*}{$\begin{array}{l}\text { Sentimento do cônjuge com } \\
\text { relação à distribuição de } \\
\text { tempo e energia }\end{array}$} & $\begin{array}{l}\text { Muito insatisfeito } \\
\text { (a) }\end{array}$ & $72,58 \underline{a} \uparrow$ \\
\hline & Insatisfeito (a) & $71,30 \mathrm{a} \uparrow$ \\
\hline & $\begin{array}{l}\text { Nem satisfeito (a), } \\
\text { nem insatisfeito } \\
\text { (a) }\end{array}$ & $68,02 \underline{a} \uparrow$ \\
\hline & Satisfeito (a) & $62,29^{b} \downarrow$ \\
\hline & Muito Satisfeito & $58,00^{\mathrm{b}} \downarrow$ \\
\hline
\end{tabular}

Fonte: Dados da pesquisa

Já em relação à distribuição média de tempo com a vida profissional versus aspectos da empresa, podemos perceber que o percentual médio de tempo gasto com a vida profissional é maior quando a carga de trabalho é de 12 ou mais horas. É também maior em relação aos executivos que trabalham sempre nos fins de semana e freqüentemente ou sempre respondem e-mails relacionados ao trabalho fora do horário normal de trabalho.

Tabela 7

Distribuição de tempo com a vida profissional $\mathrm{x}$ aspectos relativos à empresa

Aspectos relativos à empresa

Percentual médio de tempo gasto com a vida profissional

\begin{tabular}{lll}
\hline $\begin{array}{l}\text { Carga de trabalho por dia } \\
\text { útil. }\end{array}$ & de 8 a 9h & $62,51^{\mathrm{c}} \downarrow$ \\
\cline { 2 - 3 } & de 10 a $11 \mathrm{~h}$ & $68,45^{\mathrm{b}}$ \\
\hline
\end{tabular}


Betania Tanure, Antonio Carvalho Neto, Carolina Maria Mota Santos, Roberto Patrus Estresse, Doença do Tempo: um estudo sobre o uso do tempo pelos executivos brasileiros

\begin{tabular}{|c|c|c|}
\hline & 12 ou mais & $72,80^{\mathrm{a}} \uparrow$ \\
\hline \multirow{5}{*}{$\begin{array}{l}\text { Trabalha nos fins de } \\
\text { semana. }\end{array}$} & Nunca & $65,56^{\mathrm{c}} \downarrow$ \\
\hline & Raramente & $66,64^{\mathrm{c} \downarrow}$ \\
\hline & Às vezes & $69,61^{b, c}$ \\
\hline & Freqüentemente & $72,74 a^{a}, b$ \\
\hline & Sempre & $76,67 \underline{a} \uparrow$ \\
\hline \multirow{5}{*}{$\begin{array}{l}\text { Fora do horário normal de } \\
\text { trabalho, atende celular ou } \\
\text { responde e-mails } \\
\text { relacionados ao trabalho. }\end{array}$} & Nunca & $67,60^{\mathrm{b} \downarrow}$ \\
\hline & Raramente & $66,43^{b} \downarrow$ \\
\hline & Às vezes & $67,10^{\mathrm{b}} \downarrow$ \\
\hline & Freqüentemente & $70,45 \mathrm{a} \uparrow$ \\
\hline & Sempre & $70,64 \underline{a} \uparrow$ \\
\hline
\end{tabular}

Fonte: Dados da pesquisa

O sentimento da pessoa e do cônjuge (de acordo com a percepção do primeiro) em relação à distribuição de tempo e energia estão intimamente ligados. Na medida em que a satisfação do indivíduo aumenta, também aumenta a percepção da satisfação do cônjuge.

Tabela 8

Sentimento do executivo e do cônjuge em relação à distribuição de tempo e energia

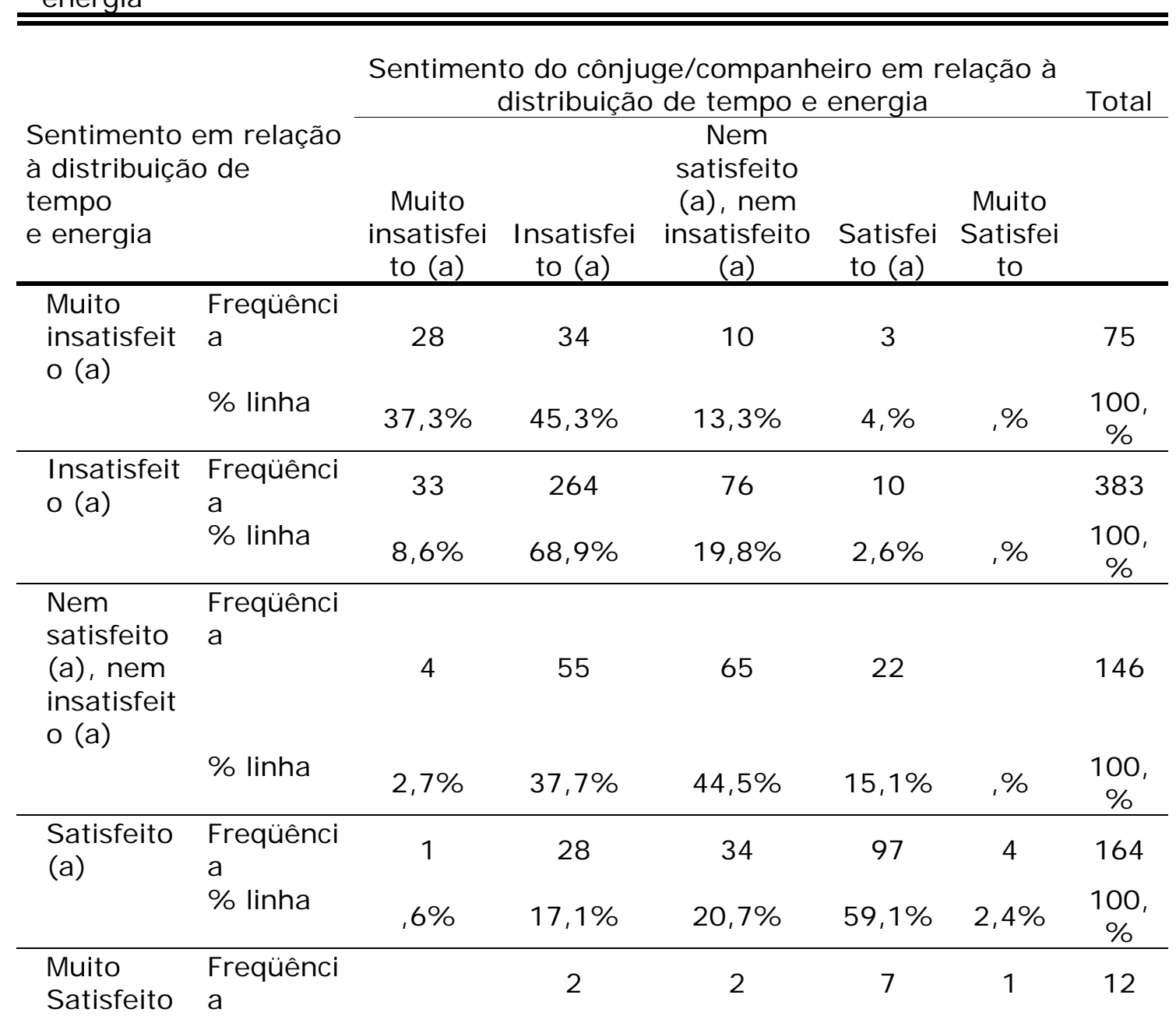


Betania Tanure, Antonio Carvalho Neto, Carolina Maria Mota Santos, Roberto Patrus Estresse, Doença do Tempo: um estudo sobre o uso do tempo pelos executivos brasileiros

\begin{tabular}{lccccccc}
\hline (a) & \% linha &,$\%$ & $16,7 \%$ & $16,7 \%$ & $58,3 \%$ & $8,3 \%$ & $\begin{array}{c}100, \\
\%\end{array}$ \\
\hline Total & $\begin{array}{l}\text { Freqüênci } \\
\text { a }\end{array}$ & 66 & 383 & 187 & 139 & 5 & 780 \\
& $\%$ linha & $8,5 \%$ & $49,1 \%$ & $24, \%$ & $17,8 \%$ &, $6 \%$ & $\begin{array}{c}100, \\
\%\end{array}$ \\
\hline \hline
\end{tabular}

Kendall: P-valor $=, 000$

Fonte: Dados da pesquisa

Também verificamos a relação do sentimento de estresse versus tempo de trabalho (carga de trabalho, trabalho nos finais de semana, etc), como se percebe na tabela 9 .

Os entrevistados que trabalham de 8 a 9 horas são os menos estressados tanto na vida privada como na profissional e no geral. Já os mais estressados são aqueles que têm carga de trabalho de 12 horas ou mais.

As pessoas que trabalham em empresas que estão passando por alguma mudança radical são as mais estressadas na vida profissional e no geral.

Tabela 9

Tempo de trabalho $\times$ Estresse

\begin{tabular}{|c|c|c|c|c|}
\hline \multirow{2}{*}{\multicolumn{2}{|c|}{ Características da empresa }} & \multicolumn{3}{|c|}{ Stress } \\
\hline & & \multirow{2}{*}{$\begin{array}{c}\mathrm{Na} \\
\text { vida } \\
\text { privad } \\
\text { a } \\
\begin{array}{c}1,99 \\
\mathrm{~b} \downarrow\end{array}\end{array}$} & \multirow{2}{*}{$\begin{array}{c}\begin{array}{c}\text { Na vida } \\
\text { profission } \\
\text { al }\end{array} \\
2,44^{\text {C }} \downarrow\end{array}$} & \multirow{2}{*}{$\begin{array}{l}\text { No geral } \\
2,30^{\complement} \downarrow\end{array}$} \\
\hline \multirow{3}{*}{ Carga de trabalho } & de 8 a $9 \mathrm{~h}$ & & & \\
\hline & de 10 a $11 \mathrm{~h}$ & $2,13^{a}$ & $2,73^{b}$ & $2,52^{b}$ \\
\hline & 12 ou mais & $\begin{array}{c}2,20 \underline{a} \\
\uparrow\end{array}$ & $2,97 \underline{a} \uparrow$ & $2,71 \mathrm{a} \uparrow$ \\
\hline \multirow{5}{*}{$\begin{array}{l}\text { Trabalha nos fins de } \\
\text { semana }\end{array}$} & Nunca & $1,94^{\mathrm{b} \downarrow}$ & $2,48^{b \downarrow}$ & $2,28^{\mathrm{C}} \downarrow$ \\
\hline & Raramente & $\begin{array}{c}2,08 \\
a, b\end{array}$ & $2,68^{a, b}$ & $2,48^{b, c}$ \\
\hline & Às vezes & $\underset{a, b}{2,16}$ & $2,78^{a, b}$ & $2,57^{a, b}$ \\
\hline & $\begin{array}{l}\text { Freqüentemen } \\
\text { te }\end{array}$ & $\begin{array}{c}2,27 \underline{a} \\
\uparrow\end{array}$ & $3,00 \geqq \uparrow$ & 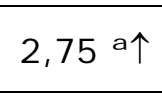 \\
\hline & Sempre & $\underset{a, b}{2,00}$ & $2,73^{a, b}$ & $2,47^{b, c}$ \\
\hline \multirow{4}{*}{$\begin{array}{l}\text { Atende o celular ou } \\
\text { responde e-mail fora do } \\
\text { horário normal de } \\
\text { trabalho }\end{array}$} & Nunca & $\begin{array}{c}2,00 \\
b \downarrow\end{array}$ & $2,46^{\mathrm{c}} \downarrow$ & $2,27^{\mathrm{C} \downarrow}$ \\
\hline & Raramente & $2,05^{a, b}$ & $2,66^{b, c}$ & $2,49^{a, b}$ \\
\hline & Às vezes & $2,06^{a, b}$ & $2,61^{\mathrm{c}} \downarrow$ & $2,44^{b, c}$ \\
\hline & $\begin{array}{l}\text { Freqüentemen } \\
\text { te }\end{array}$ & $2,17^{a, b}$ & $2,85^{a, b}$ & $2,60^{a, b}$ \\
\hline
\end{tabular}




\begin{tabular}{llccc}
\hline & Sempre & $\begin{array}{c}2,24 \\
\underline{\mathrm{a}} \uparrow\end{array}$ & $2,94 \underline{\mathrm{a} \uparrow}$ & $2,67 \underline{\mathrm{a}} \uparrow$ \\
\hline \hline $\begin{array}{l}\text { A empresa está vivendo } \\
\text { uma mudança radical }\end{array}$ & $\operatorname{Sim}$ & $2,83 \uparrow$ & $2,60 \uparrow$ \\
\cline { 2 - 4 } & Não & $2,67 \downarrow$ & $2,47 \downarrow$ \\
\hline \hline
\end{tabular}

Fonte: Dados da pesquisa

Pessoas que frequentemente trabalham nos fins de semana são mais estressadas. Em contrapartida, as que nunca trabalham nos fins de semana são as menos estressadas, tanto na vida privada como na profissional e no geral.

Os indivíduos que nunca atendem o celular ou respondem e-mails relacionados ao trabalho fora do horário normal de trabalho são menos estressados que os demais. Já os mais estressados são os que atendem o celular ou respondem e-mails fora do horário normal de trabalho sempre.

Os dados da pesquisa apontam claramente que o tempo de trabalho, quando excessivo, é um dos fatores que provoca sentimento de estresse para os executivos participantes da pesquisa. A extrapolação das atividades de trabalho para o ambiente familiar, seja pelo atendimento do celular, seja pela leitura dos e-mails, também é um fator associado aos sintomas do estresse, de forma significativa.

\section{Considerações finais}

Sem deixar de considerar outros fatores que podem desencadear desordens psicossomáticas, o corte para a apresentação dos dados foi o tema "tempo". Diante disto, os dados da pesquisa sugerem que o estresse está diretamente relacionado com a variável tempo ou, melhor dizendo, com o uso do tempo que os executivos fazem. Os executivos que se sentem estressados trabalham mais, em termos de horas de trabalho, do que aqueles que se sentem menos estressados.

Os executivos que ocupam cargos estratégicos nas grandes empresas operando no Brasil percebem o tempo da forma elástica, como se coubessem mais do que as 24 horas cronológicas. O advento das tecnologias modernas, como o e-mail e o telefone celular desfaz o limite territorial entre o ambiente de trabalho e o ambiente privado e catapulta esta ilusão. Certamente podemos fazer hoje muito mais atividades do que fazíamos no passado, mas o descontrole e o exagero são enormes, e aí o contexto propício ao aumento do estresse está dado.

Tais recursos permitem a economia de tempo, por um lado, mas, por outro, sobrecarregam o executivo. Ganhar um telefone corporativo, ou um lap top, por exemplo, é amplamente considerado um "presente de grego", um cavalo de Tróia que aprisiona o presenteado 
ao trabalho 24 horas por dia. Uma das frases mais ouvidas na pesquisa foi "vendi minha alma ao diabo", o que leva a uma imediata e livre associação com o personagem Fausto da obra de Goethe: ganhamos um presente do diabo, mas ele cobra seu preço. Da mesma forma que beneficia, a tecnologia escraviza, rouba-nos o sossego, nos torna acessíveis 24 horas por dia, muitas vezes quando não temos a menor vontade de sermos encontrados. Popcorn apontava, na década de 1990, a tendência "99 vidas" para descrever os múltiplos papéis do homem moderno. Poderíamos acrescentar que somos convidados a exercer esses múltiplos papéis ao mesmo tempo, o que torna o desgaste no trabalho e na família muito mais complexo. No fordismo, o tempo do trabalhador era determinado pela esteira rolante à qual estava "infernalmente preso" por 8 horas. A esteira retirou do trabalhador o controle sobre o tempo de produção, alienado que já estava do processo de produção, dada a divisão do trabalho. Atualmente, parece haver uma esteira rolante virtual, que funciona on line, dia e noite. No caso dos executivos objeto desta pesquisa, isto ficou ainda mais evidente. Curiosamente, essa esteira virtual, a alienar do trabalhador o controle do tempo, é desejada e almejada pelos executivos. Quando alcança o topo da hierarquia empresarial, o executivo passa a ter o controle sobre o processo produtivo. Em tese, poderia ter o controle sobre o tempo também. Mas, em geral, ele não se considera dono da sua própria agenda.

O tempo se transforma em algo externo, autônomo, abstrato, a exigir do executivo o culto ao trabalho, a valorização do sacrifício em prol da organização. A cultura do workaholic recompensa a sua dedicação e minimiza o seu sentimento de insegurança diante de um mundo empresarial competitivo e selvagem. Não foram poucas as referências que ouvimos dos executivos contando do espanto de seus pares estrangeiros sobre a enorme jornada de trabalho dos executivos brasileiros. Ou seja, este segmento profissional no Brasil é mais workaholic do que os seus consortes norte-americanos, que criaram o termo.

Presa deste excessivo controle de si pelo outro, pela organização, o executivo, estressado, é muitas vezes vítima do fato de não se fazer centro de si mesmo: ele quer atender a uma demanda do outro, de um outro às vezes invisível (como uma difusa "globalização", "as exigências de alta competitividade", "o atual ambiente de negócios"), às vezes não tão invisível assim (há chefes que transmitem para baixo da cadeia hierárquica a pressão que vem dos seus superiores hierárquicos). Este outro invisível revela a heteronomia. A norma é exterior, você nada pode fazer, só resta submeter-se. Metas ousadas são perseguidas e cumpridas para atender uma demanda externa. 0 reconhecimento material e simbólico é acompanhado dos efeitos colaterais, entre eles o estresse. 
Em se tratando de altos executivos, que têm o poder de 'fazer e acontecer' numa organização, fica a intrigante questão sobre a possibilidade efetiva destes imporem limites à excessiva demanda de trabalho. De algum modo, esse limite acaba sendo imposto quando o corpo adoece. O depoimento do executivo workaholic que, depois da crise de estresse, reviu sua maneira de lidar com o tempo é alvissareiro.

Tecendo um paralelo da situação do executivo com a relação do homem antigo com o tempo natural, se os principais executivos das grandes organizações, público-alvo de nossa pesquisa, repensassem seu conceito de tempo, alinhando-o mais com o respeito aos limites naturais do organismo, incluindo uma saudável maior separação entre a esfera profissional e a esfera privada, efeitos benéficos desta postura poderiam irradiar-se por toda a organização. Em nossa pesquisa encontramos alguns exemplos desta sabedoria. Em um caso, o presidente da empresa ordenou que as luzes do prédio da matriz fossem desligadas às 20 horas, numa tentativa clara de alinhamento à concepção de tempo natural. Curiosamente, tratou-se também de um recurso externo, heterônimo, de fora para dentro.

A associação entre estresse e tempo aponta um interessante campo para novas pesquisas. Em tese, um executivo autocentrado seria capaz de impor limites às demandas empresariais, a ponto de ter algum controle sobre o seu tempo. Por outro lado, aquele executivo que elege o outro como seu centro seria incapaz de ter domínio sobre o seu tempo, vítima que é da vantagem secundária que lhe traz o reconhecimento desse outro, visível ou invisível. O estudo do estresse aponta, assim, para a investigação da complexa relação entre os fatores ambientais e os psicológicos, que se objetivam na (in)capacidade de controle sobre o próprio tempo.

Contra a afirmação de Sêneca, que disse que "não é dos lugares o mal de que sofremos, mas de nós", um amigo retorquiu: "isso é porque ele não trabalhou na minha empresa"! Diz o ditado antigo que "tempo é questão de prioridade". Mas e se a prioridade for a empresa? Em última análise, tempo e estresse remontam à antiga e atual questão do comportamento organizacional: como conciliar os interesses individuais com os interesses da organização? Pensar o tempo como um limite pode ser uma saída. Se esse limite não pode mais ser imposto pela natureza, como no tempo do relógio de sol, que o seja pela autodisciplina e pela construção de processos administrativos razoáveis e humanos.

\section{Referências}

Albrecht, K. (1990). O gerente e o estresse: faça o estresse trabalhar para você. (2. ed.). Rio de Janeiro: J. Zahar, 
Arnold, J., Cooper, C. L. \& Robertson, I. T. (1995). Work psychology: understanding human behavior in the workplace. (2. ed.). London: Pitman, 1995.

Barnnet, J. E. (1998). Time's pendulum: from sundials to atomic clockes, the fascinating history of timekeeping and how our discoveries changed the world. New York: Harvest Ed.

Carvalho Neto, A., Tanure, B., Santos, M.C. M \& Lima, G.S.(2012). Executivos Brasileiros: na contramão do perfil deificado da liderança transformacional. Revista Ciência da Administração, 14(32), 35-49.

Cooper, C. L., Cooper, R. D. \& Eaker, L. H. (1988). Living with stress. London: Peguin Books.

Couto, H. A. (1987). Stress e qualidade de vida dos executivos. Rio de Janeiro: Editora COP.

Creswell, J. W. (2003). Research Design: qualitative, quantitative and mixed method approaches. London: Sage.

Descartes, R. (1989). El mundo; tratado de la luz. Barcelona: Anthropos.

Fraser, T. M. (1983). Human stress, work and job satisfaction: a critical approach. Occupation safety and health series. Geneva: International Labour Office Geneva, 72p.

Goldberg, P. (1980). A saúde dos executivos: como identificar sinais de perigo para a saúde e levar a melhor contra o estresse. Rio de Janeiro: Zahar Editores.

Landes, D. (1983). Revolution in time: clocks and the making of the modern world. Harvard University Press.

Limongi-França, A. C., Rodrigues, A. L. (1996). Stress e trabalho: guia básico com abordagem psicossomática. São Paulo: Atlas.

Lipp, M. E. N. (1996). Pesquisas sobre stress no Brasil: saúde, ocupações e grupos de risco. Campinas, São Paulo: Papirus.

Marconi, M. de A. \& Lakatos, E. M. (1999). Técnicas de pesquisa: planejamento e execução de pesquisas, amostragens e técnicas de pesquisas, elaboração, análise e interpretação de dados. (2 ed.). São Paulo: Atlas.

Mattar, F. N. (1999). Pesquisa de marketing: metodologia, planejamento. (5. ed.). São Paulo: Atlas.

Mendes, A. L. A. (2000). Situação de trabalho e estresse ocupacional: um estudo de caso com os motoristas de transporte urbano por ônibus. Dissertação de Mestrado em Administração. Universidade Federal de Minas Gerais, Belo Horizonte, MG, Brasil.

Mendes, A. L. de A. \& Moraes, L. F. R. (2001). Situação de trabalho e estresse ocupacional: um estudo de caso com os motoristas de transporte urbano por ônibus. Anais... Campinas: XXV Encontro da ANPAD, CD-ROM. Campinas, SP, Brasil.

Metzker, C. A. B. , Moraes, L. F. R. \& Zille, L. (2012). O Fisioterapeuta e o Estresse no Trabalho: Estudo em um Hospital 
Betania Tanure, Antonio Carvalho Neto, Carolina Maria Mota Santos, Roberto Patrus Estresse, Doença do Tempo: um estudo sobre o uso do tempo pelos executivos brasileiros

Filantrópico de Belo Horizonte/MG. Revista Gestão \& Tecnologia, 12(3), 174-196.

Moraes, L. F. R., Kilimnik, Z. M. (1992). As dimensões básicas do trabalho, qualidade de vida e stress: uma análise em profissões de impacto na sociedade. (Relatório de pesquisa/1992). Belo Horizonte: CEPEAD/UFMG. Moraes, L. F. R.; Pereira, L. Z.; Lopes, H. E. G.; Rocha, D. B., Ferreira, S. A. A., Portes, P. C. P. (2001). Estresse e Qualidade de vida no trabalho na Polícia Militar do Estado de Minas Gerais. In ENANPAD - Encontro Nacional dos Programas de PósGraduação em Administração. Anais... Campinas: XXV Encontro da ANPAD 2001. CD-ROM. Campinas, SP.

Moraes, L. F. R. \& Sicoli, C. R. (2004). Qualidade de vida e fontes de pressão no trabalho do consultor organizacional em Belo Horizonte. Revista Gestão e Tecnologia, 3(1), 1 - 24.

Munford, L. (1934). Tecnics and civilization. London: Routledge Et Kegan Paul.

Rio, R. P. (1995). O fascínio do stress. Belo Horizonte: Del Rey.

Sant'anna, A. S., Moraes, L. F. R., Kilimnik \& Zélia M. (2003). Superhomens, superempresas? (pp. 1-16). Nova Lima: Fundação Dom Cabral

Selye, H. (1959). Stress: a tensão da vida. São Paulo: IBRASA,.

Selye, H. (1965). Stress: a tensão da vida. (2. ed.). São Paulo: IBRASA.

Selye, H. (1974). Stress without distress. Filadélfia: Lippincott.

Tanure, B., Carvalho Neto, A. \& Andrade, J. O. (2007). Executivos: sucesso e (in) felicidade. Rio de Janeiro: Elsevier.

Zille, L., Moraes, L. F. R., Marques, A. L. \& Silva, A. A. R. (2001). Qualidade de vida e estresse ocupacional nas alturas: $O$ caso dos aeronautas brasileiros. Revista de Ciências Humanas, 1(1), 43-59.

\section{Endereço para correspondência}

Betania Tanure

PPGA - Programa de Pós Graduação em Administração da PUC Minas

Av. I taú, no 525, Bairro Dom Cabral, CEP 30.535-012, Belo Horizonte - MG, Brasil. Endereço eletrônico: betaniatanure@pucminas.br

\section{Antonio Carvalho Neto}

PPGA - Programa de Pós Graduação em Administração da PUC Minas.

Av. Itaú, no 525, Bairro Dom Cabral, CEP 30.535-012, Belo Horizonte - MG, Brasil.

Endereço eletrônico: carvalhoneto@pucminas.br

\section{Carolina Maria Mota Santos}

PPGA - Programa de Pós Graduação em Administração da PUC Minas.

Av. I taú, no 525, Bairro Dom Cabral, CEP 30.535-012, Belo Horizonte - MG, Brasil.

Endereço eletrônico: cmotasotnas@yahoo.com.br

\section{Roberto Patrus}

PPGA - Programa de Pós Graduação em Administração da PUC Minas.

Av. I taú, no 525, Bairro Dom Cabral, CEP 30.535-012, Belo Horizonte - MG, Brasil.

Endereço eletrônico: robertopatrus@pucminas.br

Recebido em: 20/08/2012 
Betania Tanure, Antonio Carvalho Neto, Carolina Maria Mota Santos, Roberto Patrus Estresse, Doença do Tempo: um estudo sobre o uso do tempo pelos executivos brasileiros

Aceito para publicação em: 02/11/2013

Acompanhamento do processo editorial: Ana Maria Lopez Calvo de Feijoo

\section{Notas}

* Doutora em Administração, professora permanente do PPGA - Programa de PósGraduação da PUC Minas, Consultora BTA, membro do NERHURT.

** Doutor em Administração, professor permanente do PPGA da PUC Minas, bolsista de produtividade do CNPq, coordenador do NERHURT - Núcleo de Estudos em Recursos Humanos e Relações de Trabalho.

*** Doutora em Administração, professora da PUC Minas Campus Betim, membro do NERHURT.

**** Doutor em Filosofia, professor permanente do PPGA da PUC Minas, Pesquisador Mineiro pela FAPEMIG.

Agradecemos à FAPEMI G e ao CNPq pelo apoio à pesquisa. 